Available online on 30.10.2020 at http://jddtonline.info
Open Access to Pharmaceutical and Medical Research
unrestricted non-commercial use, provided the original work is properly cited

Open 1 Access

\title{
Phenolic content and antioxidant activity of ethanolic extracts from Citrus sinensis L. and Citrus reticulata L. fruits
}

\author{
Assia Bentahar, Amel Bouaziz*, Saliha Djidel and Seddik Khennouf \\ Laboratory of Phytotherapy Applied to Chronic Diseases, Faculty of Natural and Life Sciences, Ferhat Abbas University Setif 1, Setif 19000, \\ Algeria
}

\begin{abstract}
Citrus fruits, in particular the genus Citrus, are very rich in antioxidants which have beneficial effects on human health. The objective of this study was to evaluate the phenolic content and the antioxidant activity of the ethanolic extracts from orange (Citrus sinensis L.) and mandarin (Citrus reticulata L.) fruits. The quantitative estimation of the total phenolic content in the two extracts revealed their richness in these compounds. The results obtained showed that the polyphenols content were $159.66 \pm 2.62 \mathrm{mg} \mathrm{GAE} / \mathrm{g}$ of dry extract and $127.33 \pm 2.32 \mathrm{mg}$ GAE / g of dry extract for $C$. sinensis and $C$. reticulata, respectively.The quantification of flavonoids content showed that the ethanolic extracts of $C$. sinensis and C. reticulata contained $0.85 \pm 0.01 \mathrm{mg} \mathrm{QE} \mathrm{/} \mathrm{g} \mathrm{of} \mathrm{dry} \mathrm{extract} \mathrm{and} 0.876 \pm 0.073 \mathrm{mg} \mathrm{QE} \mathrm{/} \mathrm{g} \mathrm{of} \mathrm{dry} \mathrm{extract,} \mathrm{respectively.} \mathrm{Whereas,} \mathrm{the}$ tannins contents were $46.32 \pm 1.02 \mathrm{mg} \mathrm{TAE} / \mathrm{g}$ of dry extract for $C$. sinensis and $47.65 \pm 1.36 \mathrm{mg} \mathrm{TAE} / \mathrm{g}$ of dry extract for $C$. reticulata. In vitro antioxidant activity was evaluated using two tests: the reducing power and the hydroxyl radical scavenger test. The evaluation of the two extracts by the ferric iron reducing power test showed an $\mathrm{EC}_{50}$ value of $0.882 \pm 0.037 \mathrm{mg} / \mathrm{ml}$ for $C$. sinensis extract and an $\mathrm{EC}_{50}$ of $1.085 \pm 0.068$ $\mathrm{mg} / \mathrm{ml}$ for C. reticulata extract. In addition, $C$. sinensis and C. reticulata showed good hydroxyl radical scavenging effect with $\mathrm{IC}_{50}$ values of 0.303 $\pm 0.026 \mathrm{mg} / \mathrm{ml}$ and $0.572 \pm 0.100 \mathrm{mg} / \mathrm{ml}$ for $C$. sinensis and C. reticulata, respectively. These results suggested that these fruit extracts could be good sources of phenolic compounds and ingredients with high antioxidant potential.
\end{abstract}

Keywords: Citrus sinensis, Citrus reticulata, Polyphenols, Flavonoids, Tannins, Antioxidant activity.

Article Info: Received 04 Sep 2020; $\quad$ Review Completed 17 Oct 2020; $\quad$ Accepted 22 Oct 2020; $\quad$ Available online 30 Oct 2020

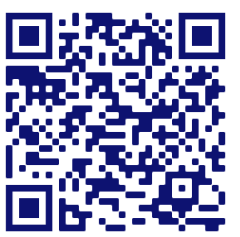

Cite this article as:

Bentahar A, Bouaziz A, Djidel S, Khennouf S, Phenolic content and antioxidant activity of ethanolic extracts from Citrus sinensis L. and Citrus reticulata L. fruits, Journal of Drug Delivery and Therapeutics. 2020; 10(5-s):308-313 http://dx.doi.org/10.22270/jddt.v10i5-s.4537

Amel Bouaziz, Laboratory of Phytotherapy Applied to Chronic Diseases, Faculty of Natural and Life Sciences, Ferhat Abbas University Setif 1 , Setif 19000, Algeria

\section{INTRODUCTION}

Oxidative stress is an imbalance between oxidants and antioxidants. To protect the organism against oxidative stress, the body has a very complex antioxidant network composed of enzymes, iron and copper transporter proteins, vitamins, carotenoids, polyphenols, flavonoids, trace elements as selenium and other small molecules as glutathione. Most of these antioxidants are found in fruits and vegetables in their various organs either leaves, flowers or roots, which reinforces all their interest in the prevention of various pathologies 1 . Therefore, it is interesting to study medicinal plants and foods of plant origin that are daily and widely used in the field of biopharmaceutical research, due to their easy access, low cost and multiple therapeutic properties.
Citrus fruits are consumed around the world as an excellent source of vitamin $\mathrm{C}$, which is a powerful natural antioxidant that strengthens the body's immune system and they have been used in traditional medicine as stomach tonic, astringent, carminative and antiscorbutic agents 2 . In addition, these fruits are used also to treat conditions such as constipation, cramps, colic, diarrhea, bronchitis, tuberculosis, cough, cold, menstrual disorders, angina, hypertension, anxiety, depression and stress 3. Citrus species exhibited numerous bioactivities as antioxidant 4 , anti-inflammatory 5 , antimicrobial 6 , anticancer, antiallergic ${ }^{4}$ and neuroprotective activities 7 , as well as pulmonary fibrosis inhibitors 8 , antiobesity and antihyperglycemic agents ${ }^{9}$. The aim of this work was to quantify the content of phenolic compounds and to study the in vitro antioxidant activity of the ethanolic extracts from the fruit pulp of Citrus sinensis and Citrus reticulata. 


\section{MATERIALS AND METHODS}

\section{Preparation of ethanolic extract}

These citrus fruits were obtained from a market in Setif region, located in Northeastern Algeria. The fruits purchased were of good quality, without damage, washed in water, peeled, cut in half, seedless and quickly grinded. The ethanolic extract was obtained by maceration in water/ ethanol mixture (20:80) for 5 days in the dark with agitation every 24 hours at. The resultant extract was filtered through Wattman paper and the solvent was removed by rotary evaporator under reduced pressure at $45^{\circ} \mathrm{C} 10$.

\section{Determination of total polyphenols content}

The total phenolic content of the extracts was determined according to Folin-Ciocalteu method Li et al. ${ }^{11}$, with some modifications. $100 \mu \mathrm{l}$ of each extract was mixed with $500 \mu \mathrm{l}$ of Folin-Ciocalteu reagent (diluted 10 times) and incubated at room temperature for $4 \mathrm{~min}$. Then, $400 \mu \mathrm{l}$ of $7.5 \%$ sodium carbonate solution was added and further incubated for $1 \mathrm{~h}$ $30 \mathrm{~min}$ at room temperature. The absorbance of all samples was measured at $760 \mathrm{~nm}$ and the results are expressed in milligrams of gallic acid equivalents per gram dried weight (mg GAE/g DW). All samples were analyzed in three replications.

\section{Determination of total flavonoids content}

Measurement of flavonoid concentration in extracts was based on the method described by Bahorun et al.12. Each sample $(1 \mathrm{ml})$ was added to $1 \mathrm{ml}$ of aluminum chloride $\left(\mathrm{AlCl}_{3}\right)$ solution $(2 \%)$ and allowed to stand at room temperature for $10 \mathrm{~min}$. The absorbance of the mixture was measured at $430 \mathrm{~nm}$ against the same mixture without the sample as a blank. Total flavonoid content was expressed as quercetin equivalent per gram dried weight (mg QE /g DW).

\section{Determination of tannins content}

The capacity to precipitate hemoglobin was determined by using bovine fresh blood according to the method described by Gharzouli et al. ${ }^{13}$. Briefly, a volume of each fruit extract was mixed with an equal volume of hemolysed bovine blood (absorbance $=1.6$ ). After $20 \mathrm{~min}$, the mixture was centrifuged at $4000 \mathrm{rpm}$ for $10 \mathrm{~min}$, and the absorbance of the supernatant was measured at $756 \mathrm{~nm}$. Results were expressed as mg equivalent tannic acid per gram dried weight (mg TAE/g DW).

\section{Evaluation of antioxidant activity}

\section{The hydroxyl radical scavenging activity}

The hydroxyl radical scavenging activity was determined according to the method described by Smirnoff et al. ${ }^{14}$. The reaction mixture contains $1 \mathrm{ml}$ of $1.5 \mathrm{Mm}$ of $\mathrm{FeSO}_{4}, 0.7 \mathrm{ml}$ of 6 $\mathrm{Mm}$ of hydrogen peroxide, $0.3 \mathrm{ml}$ of $20 \mathrm{~mm}$ of sodium salicylate and $1 \mathrm{ml}$ of the different concentrations of the extracts to be tested. After incubation for one hour at $37 \mathrm{C}{ }^{\circ} \mathrm{C}$, the absorbance is taken at a wavelength of $562 \mathrm{~nm}$. The scavenger effect of the hydroxyl radical is calculated using the following equation:

$\mathrm{I} \%=100$ (A control - A sample) $/$ A control

Where A control is the absorbance of the blank solution (containing all reagents except the test compound), and A sample is the absorbance in the presence of the test compound. Extract concentration providing $50 \%$ inhibition (IC50) was calculated from the plot of inhibition percentage against extract concentration.

\section{Reducing power}

The reducing power was measured using the method of Chung et al. ${ }^{15}$. An aliquot of each sample or BHT $(0.1 \mathrm{ml})$ was mixed with $0.1 \mathrm{ml}$ of Phosphate buffer (200mM, pH6.6) followed $0.1 \mathrm{ml}$ of $1 \%$ potassium ferricyanide $\left[\mathrm{K}_{3} \mathrm{Fe}(\mathrm{CN})_{6}\right]$. After incubation in water bath at $50^{\circ} \mathrm{C}$ for $20 \mathrm{~min}, 0.25 \mathrm{ml}$ of $10 \%$ trichloroacetic acid was added into the mixture, and then followed by centrifugation at $3000 \mathrm{rpm}$ for $10 \mathrm{~min}$. Then the resultant supernatant $(0.25 \mathrm{ml})$ was mixed with $0.25 \mathrm{ml}$ of distilled water and $0.5 \mathrm{ml}$ of $0.1 \%$ ferric chloride $\left(\mathrm{FeCl}_{3}\right)$, and the absorbance was measured at $700 \mathrm{~nm}$ against a blank. Increased absorbance of the reaction mixture indicated increased reducing power. The results are expressed in effective concentration at $50 \%\left(\mathrm{EC}_{50}\right)$ which reflected the concentration of antioxidant used to achieve an absorbance of 0.5 .

\section{Statistical analysis}

Statistical analysis was performed using Graph Pad Prism (version 5.01 for Windows). In vitro results were expressed as mean \pm standard deviation (SD) and were analyzed by one way analysis of variance (ANOVA) followed by Dunnet's test. The P-values less than 0.05 were considered statistically significant.

\section{RESULTS AND DISCUSSION}

Extraction is an important step in the isolation of bioactive compounds from plants. The extraction process is based on the difference in solubility of the compounds of a mixture in a solvent ${ }^{16}$.

\section{Total polyphenols, flavonoids and tannins content}

Plant polyphenols are secondary metabolites characterized by one or more hydroxyl groups binding to one or more aromatic rings. Several thousand polyphenolic molecules have been identified in higher plants, including edible ones. Plant polyphenols are divided into two major groups, flavonoids and non-flavonoids. Flavonoids can be divided into flavanols, flavonols, anthocyanidins, flavones, flavanones, and chalcones. Non-flavonoids include stilbenes, phenolic acids, saponins, and tannins 17. Among the important biological properties exhibited by plant polyphenols, their antioxidant activity has raised a great interest $17,18,19$.

Table 1 represented the amount of total polyphenols, flavonoids and tannins contents in the ethanolic extracts from $C$. sinensis and C.reticulata. The results showed that the ethanolic extract of $C$. sinensis exhibited the highest total phenolic content $(159.666 \pm 2.625 \mathrm{mg} \mathrm{GAE} / \mathrm{g}$ DW $)$. While, the contents of flavonoids in ethanolic extracts from $C$. sinensis and C.reticulata are close with values of $0.85 \pm$ $0.012 \mathrm{mg}$ QE $/ \mathrm{g}$ DW and $0.876 \pm 0.073 \mathrm{mg} \mathrm{QE} / \mathrm{g}$, respectively. Also, the results showed the richness of orange and mandarin extracts in tannins with converging values $(46.32 \pm 1.02 \mathrm{mg} \mathrm{TAE} / \mathrm{g}$ and $47.65 \pm 1.36 \mathrm{mg} \mathrm{TAE} / \mathrm{g}$, respectively). 
Table 1: Total polyphenols, flavonoids and tannins contents in ethanolic extracts from C. sinensis and C. reticulata fruits.

\begin{tabular}{|l|l|l|l|}
\hline Extract & Polyphenols(a) & Flavonoids(b) & Tannins(c) \\
\hline C. sinensis & $159.666 \pm 2.625$ & $0.85 \pm 0.012$ & $46.32 \pm 1.02$ \\
\hline C.reticulata & $127.333 \pm 2.322$ & $0.876 \pm 0.073$ & $47.65 \pm 1.36$ \\
\hline
\end{tabular}

(a)mg Gallic acid Equivalent /g of dry extract ; (b) mg Quercetin Equivalent / g of dry extract ; (c) mg Tannic acid Equivalent /g of dry extract ; Results are expressed as means \pm SD $(n=3)$.

Abd ghafar et al. ${ }^{20}$ reported that orange ethanolic extract had a total phenolic content of $135.3 \pm 0 \mathrm{mg}$ GAE / g DW. While, Canan et al. ${ }^{21}$ showed that the total polyphenol content of orange methanolic extract was $270.56 \pm 0.67 \mathrm{mg}$ GAE / g DW and mandarin methanolic extract contained $302.38 \pm 0.91 \mathrm{mg} \mathrm{GAE} / \mathrm{g}$ DW. Recently, Zhang et al. ${ }^{22}$ have reported that the quantitative estimation of total polyphenols and flavonoids in the methanolic extract of mandarin were $8.25 \pm 0.21 \mathrm{mg} \mathrm{GAE} / \mathrm{g}$ DW and $6.38 \pm 2.21$ $\mathrm{mg}$ QE / g DW, respectively. Ultimately, it is difficult to compare our results with those in the bibliography, because of several factors which can influence the qualitative and quantitative distribution of phenolic compounds in the extracts. among these factors: the chemical nature of the compounds, the extraction method and the solvents used, the solubility of the phenolic components 23 , the origin of the plants and their cultivation and the harvest season 24,25, climatic and environmental conditions (high temperature, high exposure to the sun, drought and salinity) 26 , the different diseases that can attack them, the use of a different standard and a different calibration curve are also factors that must be taken into consideration ${ }^{27}$.

\section{Evaluation of antioxidant activity}

Polyphenolic compounds clearly improve the status of different oxidative stress biomarkers. The biological mechanisms of these possible effects have been attributed to their antioxidant properties through several possible mechanisms, such as their ability to scavenge free radicals, break radical chain reactions, directly reducing peroxides, and stimulating the antioxidative defense enzyme activities 28.

\section{Hydroxyl radical scavenging activity}

This test consists of scavenging the hydroxyl radical formed through the Fenton reaction to the reaction medium with sodium salicylate and forming a pink complex observed at an absorbance of $562 \mathrm{~nm}$.

In this study, a significant decrease in the amount of hydroxyl radicals was observed due to the scavenging ability of standard and fruit ethanolic extracts (Figure1). Figure 2 revealed that the ethanolic extract of $C$. sinensis exhibited a strongest antioxidant activity $\left(\mathrm{IC}_{50}=0.303 \pm 0.026 \mathrm{mg} / \mathrm{ml}\right.$, $\mathrm{p}<0.05)$, which is comparable to the standard vit C $\left(\mathrm{IC}_{50}= \pm\right.$ $\mathrm{mg} / \mathrm{ml}$ ). The ethanolic extract of $C$. reticulata, also showed good hydroxyl radical scavenging activity with an $\mathrm{IC}_{50}=$ $0.572 \pm 0.100 \mathrm{mg} / \mathrm{ml}(\mathrm{P}<0.001)$.

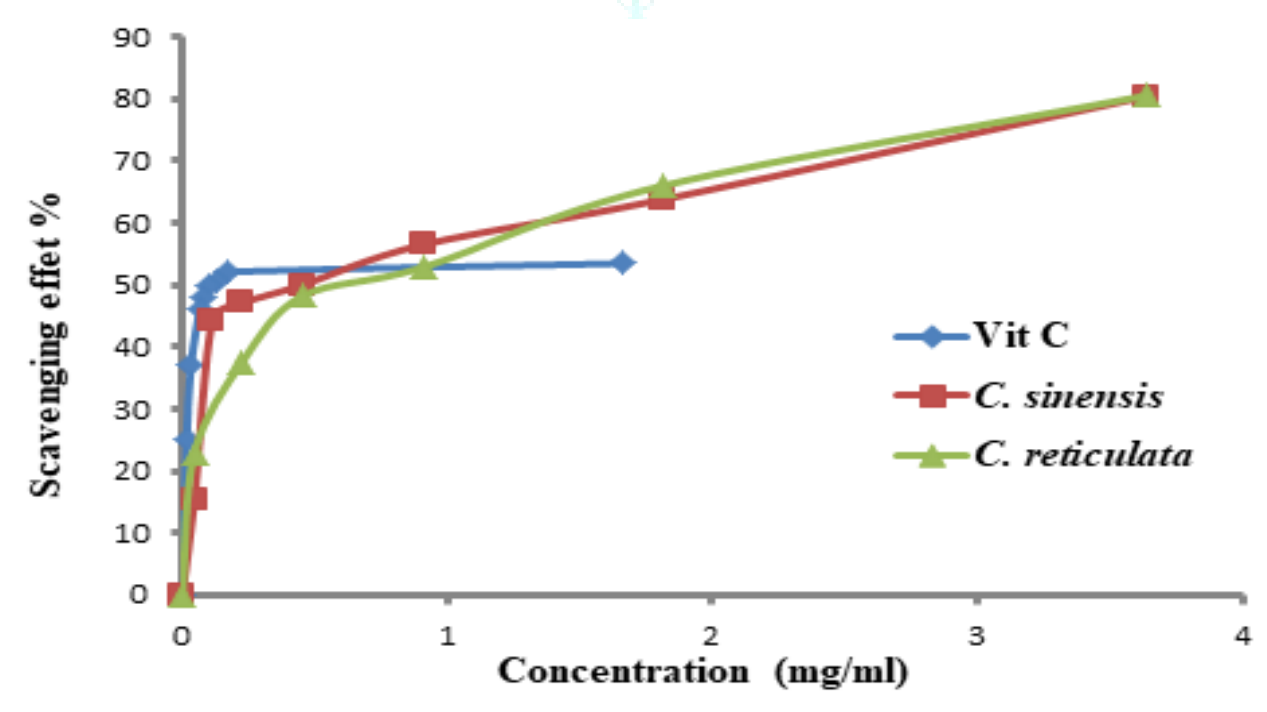

Figure 1: Hydroxyl radical scavenging activity of vitamin $C$ and fruit ethanolic extracts. 


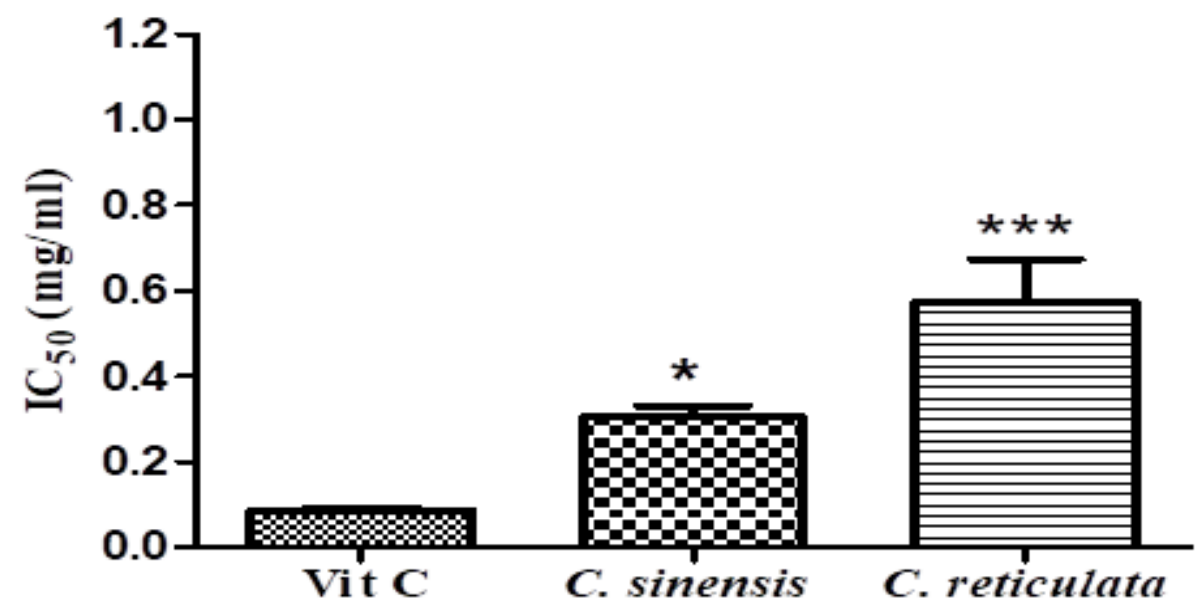

Figure 2: A comparison between ethanolic extracts of $C$. sinensis and C.reticulata in hydroxyl free radical scavenging activity. Data were presented as $\mathrm{IC}_{50}$ means $\pm \operatorname{SD}(\mathrm{n}=3) .\left({ }^{*} \mathrm{p}<0.05,{ }^{* * *} \mathrm{p}<0.001\right)$ compared to vit $\mathrm{C}$ as standard.

The obtained results may be due to the presence of polyphenols and flavonoids which have the principal contribution to the antioxidant capacity of fruits extracts. In fact, literature showed that good correlation was found between antioxidant activity and the content of polyphenols and flavonoids contents ${ }^{19}$, 29 . Albano and Miguel 30 reported that flavonoids and phenolic acids are more effective in scavenging free radicals after extraction with moderate or hydrophilic solvents. In addition, tannins are excellent scavengers of free radicals, such as iron and copper in free form because of their phenolic functions, which have a strong nucleophilic character 31,32 .

\section{Reducing power capacity}

The reducing capacity of the extracts, another significant indicator of antioxidant activity. It is attributed to reductants, which have hydrogen-donating ability, resulting in potent antioxidant activities in test samples. In addition, antioxidant activities have been reported to be directly correlated with reducing power abilities in some plant-based compounds 28 .

As shown in Figure 3, the reducing capacity was proportional to the concentration of ethanolic extracts of the two fruits and BHT as standard. As shown also in Figure 4, there was significant difference $(\mathrm{p}<0.001)$ among extracts in the reducing power with $\mathrm{EC}_{50}$ values of $0.882 \pm 0.037 \mathrm{mg} / \mathrm{ml}$ and $\mathrm{EC}_{50 \mathrm{O}} 1.085 \pm 0.068 \mathrm{mg} / \mathrm{ml}$ for C. sinensis and C.reticulata extracts, respectively compared to BHT as positive control $\left(\mathrm{EC}_{50}=0.051 \pm 0.006 \mathrm{mg} / \mathrm{ml}\right)$.

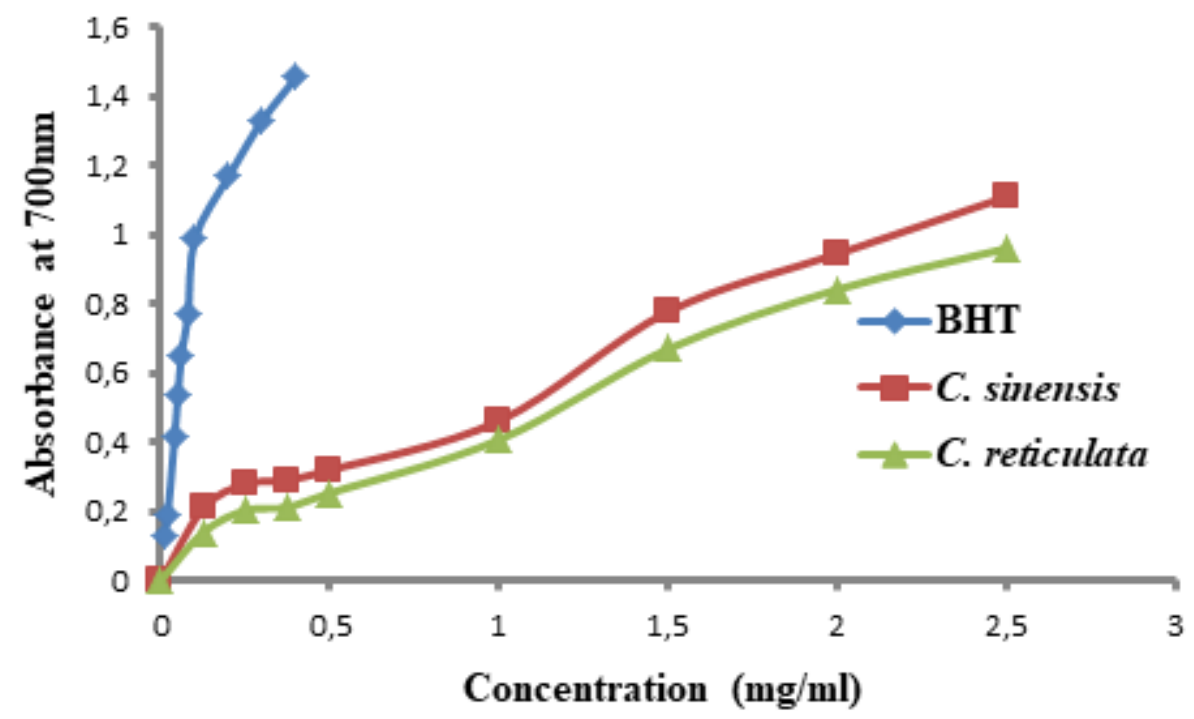

Figure 3: Reducing power capacity of standard and fruit ethanolic extracts. 


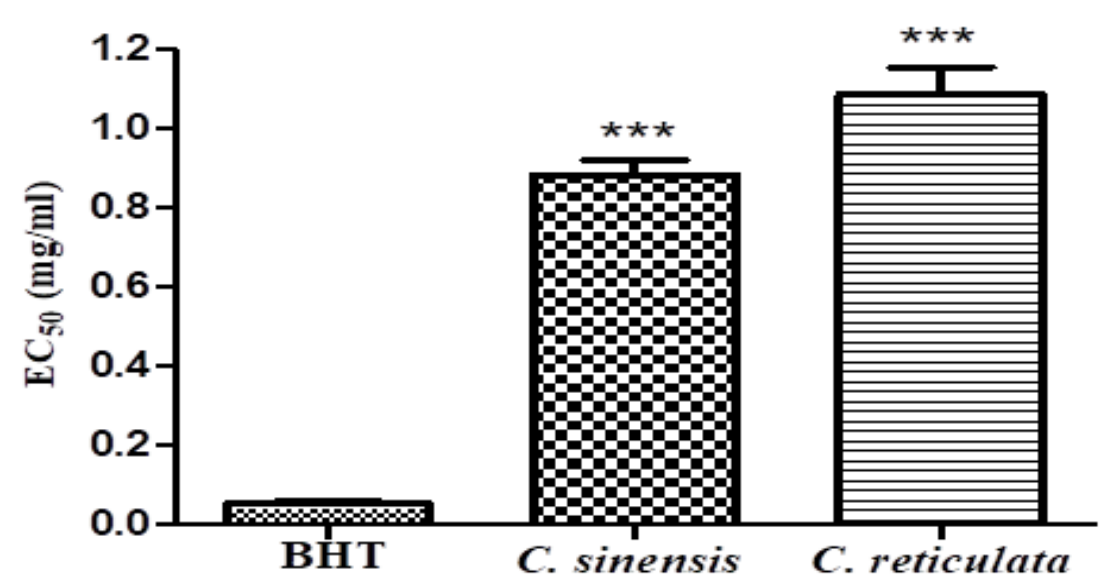

Figure 4: A comparison between ethanolic extracts of $C$. sinensis and C.reticulata in reducing power assay. Data were presented as $\mathrm{EC}_{50}$ means $\pm \mathrm{SD}(\mathrm{n}=3)$. ( $\left.{ }^{* * *} \mathrm{p}<0.001\right)$ compared to BHT as standard.

Wang et al. 33 showed that antioxidant activities have been reported to be directly correlated with reducing power abilities in some plant-based compounds. In addition, the increase in power reduction capacity may be due to the formation of reducing agents, which react with free radicals to stabilize and terminate free radical chain reactions during fermentation 34 .

\section{CONCLUSION}

This study was the first report about the antioxidant activities of two species of Citrus which are commonly available in Algeria. The results of this study showed that the ethanolic extracts of $C$. sinensis and $C$. reticulata possessed high phenolic and tannins content and exhibited good antioxidant activity by the hydroxyl radical scavenging activity and reducing power capacity methods. The use of $C$. sinensis and $C$. reticulata fruits as a natural antioxidant source appears to be an alternative to synthetic antioxidants. Further investigations are needed to determine antioxidant activity of Citrus species by in vivo methods and the exact mechanism of action for their pharmacological properties.

\section{ACKNOWLEDGEMENTS}

This work was supported by the Algerian Ministry of Higher Education and Scientific Research (MESRS), the Thematic Agency for Research in Health Sciences (ATRSS), and the General Directorate of Scientific Research and Technological Development (DGRSDT). We express our gratitude to these organizations.

\section{REFERENCES}

1. Pincemail J., Degrune F., Voussure S., Malherbe C., Paquot N. and Defraigne J.0., Effect of a diet rich in fruits and vegetables on the plasmatic antioxidant rates and of the markers of the oxidative damage, Nutrition clinique et métabolisme,2007; $21: 66-75$

2. Nakayama N., Yamaura K., Shimada M., Ueno K., Extract from peel of Citrus natsudaidai alleviates experimental chronic allergic dermatitis in mice, Pharmacognosy Research, 2013; 3:155.

3. Jaun M.J., Hernandez F., Gonzalez-Santiago 0., RamirezCabrera AM., EsquivelFerrino PC., Camacho-Corona MDR., Chemistry and Pharmacology of Citrus sinensis, Molecules, $2016 ; 21(2): 247$.

4. Xinmiao Lv., Zhao S., Ning Z., Zeng H., Shu Y., Tao O., Xiao C., Lu C., Liu Y., Les agrumes comme un trésor de métabolites naturels actifs qui peuvent potentiellement offrir des avantages pour la santé humaine, Chemistry Central Journal, 2015; 9:68.
5. Heiss E., Herhaus C., Klimo K., Bartsch H., Gerhauser C., Nuclear factor kappa B is a molecular target for sulforaphanemediated anti-inflammatory mechanisms, J Biol Chem. 2001, 276:32008-32015.

6. Espina L., Somolinos M., Loran S., Conchello P., García D., Pagán R., Chemical composition of commercial citrus fruit essential oils and evaluation of their antimicrobial activity acting alone or in combined processes, Food Control,2011; 22:896-902.

7. Ming W., Hongwu Z., Chao Z., Hongmei J., Zhuo M., Zhongmei $Z$., Identification of the chemical constituents in aqueous extract of Zhi-Qiao and evaluation of its antidepressant effect. Molecules, 2015; 20:6925-6940.

8. Xian-Mei Z., Gao-Yan W., Yang Z., Yu-Mei L., Jian-Xin L., Inhibitory effects of alkaline extract of Citrus reticulata on pulmonary fibrosis, Journal of Ethnopharmacology, 2013; 146:372-378.

9. Eri O., Jun I., Tsutomu H., Makoto S., Ryuichiro S., Anti-obesity and antihyperglycemic nomilin in mice fed a high-fat diet, Biochem Bioph Res Co. 2011; 410:677- 681.

10. Neda S., Lakic, Neda M., Mimca-Dukic, J., MBiljana I., BozinN., Antioxidant properties of Galium verum L. (Rubiaceae) extracts, Cent Eur J Biol, 20105; (3):331-337.

11. Li H.B., Cheng K.W., Wong C.C., Fan K.W., Chen F., Jiang, Y., Evaluation of antioxidant capacity and total phenolic content of different fractions of selected microalgae, Food Chemistry, 2007; 102:776.

12. Bahorun T, Gressier B, Trotin F, Brunet C, Dine T, Luyckx, Oxygen species scavenging activity of phenolic extracts from hawthorn fresh plant organs and pharmaceutical preparations. Arzneimittelforschung, 1996; 46:1086-1089.

13. Gharzouli K, Khennouf S, Amira S, Gharzouli A, Effects of aqueous extracts from Quercus ilex L. root bark, Punica granatum L. fruit peel and Artemisia herba-alba Asso leaves on ethanol-induced gastric damage in rats. Phytother Res, 1999; 13:42-45.

14. Smirnoff N, Cumbes QJ, Hydroxyl radical scavenging activity of compatible solutes. J Phytochemestry, 1989; 28: $1057-1060$.

15. Chung YC, Chen SJ, Hsu CK, Chang CT, Chou ST, Studies on the antioxidative activity of Graptopetalum paraguayense. Walther. Food Chem, 2005; 91:419-424.

16. Tiwari P, Kumar B, Kaur M, Kaur G, Kaur H., Photochemicale screening and extraction. A Review, International Pharmaceuticasciencia, 2011; 1:98-106.

17. Zhou Y, Jiang Z, Lu H, Xu Z, Tong R, Shi J., Jia G., Recent Advances of Natural Polyphenols Activatorsfor Keap1-Nrf2 Signaling Pathway, Chem. Biodivers, 2019; 16

18. Saoudi S., Khennouf S., Mayouf N., Identification and quantification of fruit phenolic compounds of Malus communis, Journal of Drug Delivery \& Therapeutics, 2019; 9(6-s):1-4.

19. Bouaziz A., Djidel S., Bentahar A., Khennouf S., Polyphenolic content, Antioxidant and Anti-inflammatory activities of Melon(Cucumis melo L. var. inodorus) Seeds, Journal of Drug Delivery \& Therapeutics. 2020; 10(2-s):22-26. 
20. Abd Ghafar MF., Prasad KN., Weng KK., Ismail A., Flavonoid, hesperidine, total phenolic contents and antioxidant activities from Citrus species. African Journal of Biotechnology, 2010; 9(3):326-330.

21. Canan I., Gündoğdu M., Seday U., Aylin oluk C., KaraşahinZ., Çağlar eroğlu E., Yazici E., Ünlü M., Determination of antioxidant, total phenolic, total carotenoid, lycopene, ascorbic acid, and sugar contents of Citrus species and mandarin hybrids. Turkish Journal of Agriculture and Forestry, 2016; 40: 894- 899.

22. Zhang H., Yang Y., Zhou Z., Phenolic and flavonoid contents of mandarin (Citrus reticulata Blanco) fruit tissues and their antioxidant capacity as evaluated by DPPH and ABTS methods. Journal of Integrative Agriculture, 2018; 17(1):256-263.

23. Mahmoudi S., Khali M., Mahmoudi N., Etude de l'extraction des composés phénoliques de différentes parties de la fleur d'artichaut (Cynara scolymus L.), Nature and Technologie, 2012; 09:35 -40.

24. Aydemir T., Ozturk R., Bozkaya L.A., Tarhan L., Effects of antioxidant vitamins $\mathrm{A}, \mathrm{C}, \mathrm{E}$ and trace elements $\mathrm{Cu}$, Se on $\mathrm{Cu} \mathrm{Zn}$ SOD, GSH-Px, CAT and LPO levels in chicken erythrocytes, Cell Biochemistry and Clinical Function,2000; 18:109-115.

25. Nckz M., Shahidi F., Phenolics in cereals, fruits and vegetables : Occurrence, extraction and analysis, Journal of pharmaceutical and Biomedical Analysis, 2006; 41:1523-1542.

26. Falleh H., Ksouri R., Chaieb K., Karray-Bouraoui N., Trabelsi N., Boulaaba M., Abdelly C., Phenolic composition of Cynara cardunculus L. organs, and their biological activities. Comptes Rendus Biologies, 2008; 331:372-379.
27. Park H.J., Cha H.C., Flavonoids from leaves and exocarps of the grape Kyoho, Korean Journal of biological Society, 2003; 7:327-330.

28. Bentahar A., Khennouf S., Bouaziz A., Baghiani A., Dahamna S., Amira S., Arrar L., Polyphenols Content and Antioxidant Activities of Selected Algerian Plants Used for Gastro-duodenal Ulcers. Der Pharma Chemica, 2016; 8(12):88-99.

29. Bouaziz A., Khennouf S., Abu Zarga M., Abdalla S, In vitro anti-oxidant, hypotensive and diuretic activities of Origanum glandulosum in rat. Bangladesh J Pharmacol, 2019; 14:17-25.

30. Albano SM., Miguel MG., Biological activities of extracts of plants grown in Portugal. Industrial Crops and Products, 2010; 1-6

31. Jung YD., Ellis LM., Inhibition of tumour evasion and angiogenesis by epigallocatechin gallate (EGCG), a major component of green tea.Int, J. Exp. Path., 2001; 82:309-316.

32. Richelle M., Tavazzi .I, Offord E., Comparison of the antioxidant activity of commonly beverages (coffe, cacao, and tea) prepared per cup serving. J. Agric. Food Chem, 2001; 49:34383442 .

33. Wang HF., Yih KH., Huang KF., Comparative study of the antioxidant activity of forty-five commonly used essential oils and their potential active components, J Food Drug Anal, 2010; 18:24-33.

34. Yen GC., Chang YC., Su SW., Antioxidant activity and active compounds of rice koji fermented with Aspergillus Candidus, Food Chem, 2003; 83:49-54. 